\title{
ALEITAMENTO MATERNO: ORIENTAÇÕES RECEBIDAS POR GESTANTES ACOMPANHADAS PELA ESTRATÉGIA SAÚDE DA FAMÍLIA
}

\author{
BREASTFEEDING: GUIDELINES RECEIVED BY PREGNANT WOMEN ASSISTED BY THE FAMILY \\ HEALTH STRATEGY
}

\author{
Maria Gabriela Cabrera Ferreira ${ }^{a^{*}}$, Maria Fernanda Pereira Gomes ${ }^{b^{*}}$, \\ Lislaine Aparecida Fracolli ${ }^{* *}$ \\ amferpgprof@gmail.com, bm_fernanda_pgomes@hotmail.com, clislaine@usp.br \\ *Universidade Paulista - São Paulo (SP), Brasil \\ **Universidade de São Paulo - São Paulo (SP), Brasil
}

Data de recebimento do artigo: 19/08/2017

Data de aceite do artigo: 16/10/2017

\section{RESUMO}

Objetivo: Identificar as orientaçôes sobre aleitamento materno recebidas pelas gestantes atendidas pela Estratégia Saúde da Família no município de Palmital/SP. Métodos: Trata-se de uma pesquisa descritiva e exploratória. Participaram da pesquisa 24 mulheres que frequentaram o grupo de educação em saúde para gestantes, cujos encontros são realizados uma vez por mês no município para todas as grávidas. $\mathrm{O}$ instrumento utilizado para coleta de dados foi um questionário elaborado pelos autores com base nas orientaçôes que a gestante deve saber sobre o aleitamento materno, contidas no Caderno de Atenção Básica $\mathrm{n}^{\circ}$ 23. Resultados: A maioria das gestantes participantes da pesquisa estão entre a faixa etária de 18 a 30 anos e possuem ensino médio completo. As gestantes são orientadas principalmente sobre a importância do aleitamento materno, sobre como o leite materno é completo e sobre complementar a amamentação com outros alimentos após seis meses. As gestantes são menos orientadas quanto a mitos, crenças, medos, preocupaçôes e fantasias relacionados ao aleitamento materno. Conclusáo: Os profissionais de saúde devem conhecer as dúvidas, medos, expectativas, mitos e crenças referentes ao aleitamento materno que as gestantes atendidas apresentam, para desmistificar as crenças consolidadas que influenciam de forma negativa na adesão ao aleitamento materno.

Palavras-chave: Aleitamento materno; Estratégia Saúde da Família; saúde da criança.

\section{ABSTRACT}

Objective: To identify the guidelines on breastfeeding received by pregnant women assisted by the Family Health Strategy in the municipality of Palmital, São Paulo, Brazil. Methods: This is a descriptive and exploratory research. Twenty-four pregnant women attending the health education group for pregnant women participated in the study, groups that have meetings once a month in the city for all pregnant women. The instrument used for data collection was a questionnaire prepared by the authors based on the guidelines that pregnant woman should know about breastfeeding contained in Basic Care Booklet No. 23. Results: Most of the pregnant women participating in the research are among the age group from 18 to 30 years old and have completed high school. The pregnant women are mainly oriented about the importance of breastfeeding, about how breast milk is complete and about how breast-feeding should be supplemented with other kinds of food after six months. Pregnant women are less oriented about the myths, beliefs, fears, worries and fantasies related to breastfeeding. Conclusion: Health professionals should be aware of the doubts, fears, expectations, myths and beliefs related to breastfeeding that pregnant women present, in order to demystify consolidated beliefs that negatively influence adherence to breastfeeding.

Keywords: Breast feeding; Family Health Strategy; child health. 


\section{Introdução}

A infância é um período em que se desenvolve grande parte das potencialidades humanas. Os distúrbios que incidem nessa época são responsáveis por graves consequências para indivíduos e comunidades ${ }^{1}$. $\mathrm{O}$ aleitamento materno é a mais sábia estratégia natural de vínculo, afeto, proteção e nutrição para a criança e constitui a mais sensível, econômica e eficaz intervençáo para redução da morbimortalidade infantil ${ }^{1}$, além de permitir um grandioso impacto na promoção da saúde integral da dupla máe/bebê e regozijo de toda a sociedade ${ }^{1}$.

A Estratégia Saúde da Família (ESF), modelo de atenção primária à saúde, possibilita o incentivo ao aleitamento materno no âmbito das famílias ${ }^{2}$. Na ESF, um dos cuidados de enfermagem que já devem ser iniciados durante o pré-natal é a promoção do aleitamento materno ${ }^{2}$. O Ministério da Saúde recomenda aleitamento materno exclusivo até os seis meses de vida ${ }^{3}$. A alimentação da mãe também é muito importante durante a amamentação, pois é dela que advêm os nutrientes para o bebể.

O enfermeiro é o profissional que, seja na rede básica, hospitalar ou ambulatorial, deve estar preparado para lidar e direcionar uma demanda diversificada e, principalmente quando se tratar de questóes relativas à mulher nutriz, deve ser capaz de identificar e oportunizar momentos educativos, facilitando a amamentação, o diagnóstico e o tratamento adequados ${ }^{2}$.

Orientar sobre amamentação requer tempo, e isso dificilmente acontece nas consultas médicas de pré-na$\mathrm{tal}^{4}$. É preciso disponibilidade para ouvir essas mulheres, a fim de que elas contem suas experiências anteriores, suas crenças e seus mitos, que sem dúvida são fatores relevantes para a futura amamentação ${ }^{2}$.

Durante o pré-natal a gestante deverá ser orientada pelo enfermeiro quanto à importância e os benefícios do aleitamento materno; mitos, crenças e medos presentes na amamentação; possíveis dificuldades na amamentação; desvantagens do uso da chupeta; alimentação adequada da nutriz; benefícios e proteção para saúde da criança proporcionados pelo aleitamento materno ${ }^{3}$. Para tanto, é importante que os enfermeiros participem de cursos periódicos sobre o aleitamento materno e busquem formas criativas de orientar as mães na amamentação ${ }^{2}$.

Nessa perspectiva, apesar de não serem escassas as pesquisas voltadas para o aleitamento materno, faz-se necessário uma avaliação do desempenho do(a) enfermeiro(a) na atenção básica e do conhecimento apreendido pelas gestantes durante o pré-natal ${ }^{2}$.
Nos últimos 23 anos, a Saúde da Família tem proporcionado cuidados de saúde à população brasileira. Nesse sentido, esta pesquisa é importante pois busca identificar o conhecimento das gestantes sobre aleitamento materno. Equipes de saúde que promovem essa prática são propulsoras da diminuição da mortalidade infantil, da diminuição da incidência das doenças prevalentes na infância e promovem a qualidade de vida das crianças menores de dois anos que são acompanhadas pela ESF.

Nessa perspectiva, este estudo teve como objetivo identificar as orientaçóes sobre aleitamento materno recebidas pelas gestantes atendidas pela ESF no município de Palmital/SP.

\section{Metodologia}

Trata-se de uma pesquisa descritiva e exploratória, da qual participaram 24 gestantes que eram atendidas pela ESF no município de Palmital no mês de julho de 2015. Essa cidade localiza-se no interior do estado de São Paulo, possui 22.041 habitantes e quatro equipes de ESF. A pesquisa foi realizada em um dos grupos de educação em saúde para gestantes que se encontravam mensalmente no município e englobavam todas as gestantes. Os temas trabalhados são: modificações fisiológicas no corpo da mulher no período gestacional, aleitamento materno, cuidados com o recém-nascido, alimentação saudável na gestação, sinais emergenciais na gestação.

$\mathrm{O}$ questionário utilizado para coleta de dados desta pesquisa foi elaborado com base nas orientações que a gestante deve receber sobre o aleitamento materno, contidas no Caderno de Atenção Básica no 23, Saúde da criança: nutriçấo infantil, aleitamento materno e alimentação complementar ${ }^{1}$.

Os questionários foram aplicados às gestantes após o término da sessão do grupo de educação em saúde, de forma que todas as gestantes presentes foram convidadas a participar da pesquisa, os pesquisadores explicaram os objetivos desta e esclareceram dúvidas. Das 26 gestantes que estavam participando do grupo, 24 aceitaram responder ao questionário. Salienta-se que foi disponibilizado o Termo de Consentimento Livre e Esclarecido para as gestantes e que a coleta de dados foi realizada após o consentimento do gestor de saúde do município e da aprovação do Comitê de Ética em Pesquisa, sob o parecer no 1.103.633. Para gestantes com idade inferior a 18 anos, obteve-se no momento da coleta de dados a autorizaçáo do responsável legal. Para organizar e analisar os dados foi utilizado o Microsoft Excel for Windows. 


\section{Resultados}

Tabela 1: Caracterização das gestantes atendidas pela ESF no município de Palmital (SP) (2015).

\begin{tabular}{|c|c|c|}
\hline Variáveis & $\mathrm{N}=24$ & $\%$ \\
\hline \multicolumn{3}{|l|}{ Idade } \\
\hline 15 a 18 anos & 5 & $20,8 \%$ \\
\hline 18 a 30 anos & 14 & $58,4 \%$ \\
\hline 30 a 40 anos & 5 & $20,8 \%$ \\
\hline \multicolumn{3}{|l|}{ Escolaridade } \\
\hline Fundamental incompleto & 2 & $8,3 \%$ \\
\hline Fundamental completo & 2 & $8,3 \%$ \\
\hline Ensino médio incompleto & 5 & $20,8 \%$ \\
\hline Ensino médio completo & 8 & $33,3 \%$ \\
\hline Superior incompleto & 4 & $16,7 \%$ \\
\hline Superior completo & 3 & $12,7 \%$ \\
\hline \multicolumn{3}{|l|}{ Número de filhos } \\
\hline 0 & 7 & $29,2 \%$ \\
\hline 1 & 11 & $45,8 \%$ \\
\hline 2 & 5 & $20,8 \%$ \\
\hline 3 ou mais & 1 & $4,2 \%$ \\
\hline \multicolumn{3}{|l|}{ Idade gestacional (IG) } \\
\hline 0 a 14 semanas & 4 & $16,7 \%$ \\
\hline 15 a 24 semanas & 3 & $12,5 \%$ \\
\hline 25 a 38 semanas & 17 & $70,8 \%$ \\
\hline \multicolumn{3}{|c|}{ Experiência de amamentaçáo } \\
\hline Sim & 15 & $62,5 \%$ \\
\hline Não & 9 & $37,5 \%$ \\
\hline
\end{tabular}

Fonte: Elaborada pelos autores, 2015.

A Tabela 1 demonstra que a maioria das gestantes participantes da pesquisa estão na a faixa etária de 18 a 30 anos, possuem o ensino médio completo, um filho, idade gestacional entre a $25^{\mathrm{a}}$ a $38^{\mathrm{a}}$ semana e já tiveram a experiência de amamentar.

Tabela 2: Características do pré-natal das gestantes atendidas pela ESF em Palmital (SP) (2015).

\begin{tabular}{lcc} 
Variáveis & N=24 & $\%$ \\
Número de consultas pré-natal & & \\
1 consulta & 1 & $4,2 \%$ \\
2 consultas & 3 & $12,5 \%$ \\
3 consultas & 1 & $4,2 \%$ \\
4 consultas & 3 & $12,5 \%$ \\
5 consultas & 4 & $16,7 \%$ \\
6 consultas & 1 & $4,2 \%$ \\
7 consultas & 2 & $8,3 \%$ \\
Mais que 7 consultas & 9 & $37,5 \%$ \\
Orientaçáo sobre aleitamento materno & & \\
Sim & 22 & $91,7 \%$ \\
Náo & 2 & $8,3 \%$ \\
Importância do enfermeiro na amamentaçáo & & \\
Nenhuma & 4 & $16,7 \%$ \\
Ajudou pouco & 3 & $12,5 \%$ \\
Ajudou muito & 10 & $41,7 \%$ \\
Sem ele(a) não teria conseguido & 2 & $8,3 \%$ \\
Náo respondeu & 5 & $20,8 \%$ \\
\hline
\end{tabular}

Fonte: Elaborada pelos autores, 2015.

A Tabela 2 mostra que a maioria teve mais que sete consultas de pré-natal, foi orientada em relação à amamentação e dizem que o enfermeiro ajudou muito nesse processo.

Tabela 3: Orientações sobre aleitamento materno às gestantes acompanhadas pela ESF no município de Palmital/SP (2015).

\begin{tabular}{|c|c|c|}
\hline Orientaçóes & $\mathrm{N}=\mathbf{2 4}$ & $\%$ \\
\hline Esclarecimento sobre mitos, crenças, medos, preocupaçóes e fantasias relacionados ao aleitamento materno. & 8 & $33,3 \%$ \\
\hline Importância do aleitamento materno. & 20 & $83,3 \%$ \\
\hline Vantagens e desvantagens do uso de leite humano. & 10 & $41,7 \%$ \\
\hline $\begin{array}{l}\text { Importância da amamentação logo após o parto e a técnica (posicionamento e pega) adequada na prevenção de complicaçôes } \\
\text { relacionadas à amamentação. }\end{array}$ & 14 & $58,3 \%$ \\
\hline Possíveis dificuldades na amamentação e meios de preveni-las (fissura mamilar, empedramento, mastite, pouco leite). & 10 & $41,7 \%$ \\
\hline Vantagens e desvantagens do uso da chupeta. & 8 & $33,3 \%$ \\
\hline $\begin{array}{l}\text { O leite materno é completo. Isso significa que até os seis meses o bebê não precisa de nenhum outro alimento (chá, suco, } \\
\text { água ou outro leite). Depois dos seis meses, a amamentaçáo deverá ser complementada com outros alimentos. }\end{array}$ & 15 & $62,5 \%$ \\
\hline O Ministério da Saúde recomenda aleitamento materno exclusivo até os seis meses de vida da criança. & 19 & $79,2 \%$ \\
\hline
\end{tabular}


Tabela 3: Continuação.

\begin{tabular}{|c|c|c|}
\hline Orientaçóes & $\mathrm{N}=24$ & $\%$ \\
\hline $\begin{array}{l}\text { Crianças que mamam têm menos riscos de sofrer doenças respiratórias, infecçóes urinárias ou diarreias, problemas que } \\
\text { podem levar a internaçốes e até à morte. }\end{array}$ & 14 & $58,3 \%$ \\
\hline $\begin{array}{l}\text { A mulher que amamenta deve consumir dieta variada, incluindo pães e cereais, frutas, legumes, verduras, derivados do leite } \\
\text { e carnes. Consumir três ou mais porçôes de derivados do leite por dia. Esforçar-se para consumir frutas e vegetais riscos em } \\
\text { vitamina A. Certificar-se de que a sede está sendo saciada. Consumir com moderaçáo café e outros produtos cafeinados. }\end{array}$ & 13 & $54,2 \%$ \\
\hline $\begin{array}{l}\text { A mulher que amamenta corre menos risco de contrair câncer de mama e de ovário. Amamentar também ajuda a mulher a } \\
\text { voltar ao peso normal mais rápido. }\end{array}$ & 14 & $58,3 \%$ \\
\hline
\end{tabular}

Fonte: Elaborada pelos autores, 2015.

$\mathrm{Na}$ Tabela 3, observa-se que as gestantes recebem principalmente as orientaçóes sobre: a importância do aleitamento materno; a recomendação do Ministério da Saúde de aleitamento materno exclusivo até os seis meses de vida da criança; como o leite materno é completo e não precisa de nenhum outro alimento (chá, suco, água ou outro leite), indicando-se complementar a amamentação com outros alimentos após os seis meses. As gestantes são menos orientadas nas seguintes informaçôes: mitos, crenças, medos, preocupaçóes e fantasias relacionados ao aleitamento materno; vantagens e desvantagens do uso da chupeta; vantagens e desvantagens do uso de leite humano; e possíveis dificuldades na amamentaçáo e meios de preveni-las (fissura mamilar, empedramento, mastite, pouco leite).

Tabela 4: Dificuldades apontadas pelas gestantes entrevistadas que já passaram pela experiência do aleitamento materno.

\begin{tabular}{lcc} 
Dificuldades & $\mathbf{N}=\mathbf{2 4}$ & \% \\
Pouco leite & 3 & $12,5 \%$ \\
\hline Pega e sucção do bebê & 8 & $33,3 \%$ \\
Mamilo invertido & 2 & $8,3 \%$ \\
\hline Fissura mamilar & 6 & $25 \%$ \\
\hline Dor na amamentação & 1 & $4,2 \%$ \\
\hline Nenhuma & 7 & $29,2 \%$ \\
\hline
\end{tabular}

Fonte: Elaborada pelos autores, 2015.

A Tabela 4 mostra que a principal dificuldade apontada pelas mães que já amamentaram foi a pega e a sucçáo do bebê, seguida pela fissura mamilar. Outro dado importante é que sete mães dizem não ter tido nenhuma dificuldade para amamentar.

\section{Discussão}

A maioria das mães entrevistadas foram orientadas em relação à importância do aleitamento materno para a criança e sobre como o leite materno é o alimento ideal devido às suas propriedades nutricionais e imunológicas, protegendo o recém-nascido de infecções, diarreia e doenças respiratórias, permitindo seu crescimento e desenvolvimento saudável, além de fortalecer o vínculo mãe-filho e reduzir o índice de mortalidade infantil ${ }^{5}$.

A Organização Mundial da Saúde (OMS) recomenda o aleitamento materno exclusivo por um período de seis meses e sob livre demanda ${ }^{6-7}$. Após esse período, a criança deve receber alimentos que complementem a sua nutrição até os dois anos ${ }^{6}$. Os benefícios do aleitamento materno, assim, podem ser constatados tanto no processo de crescimento e desenvolvimento de lactentes quanto para a criança, a mãe, a família, a sociedade e o Estado ${ }^{6}$. Para isso, é necessário que o aleitamento se inicie o mais precocemente possível e que o bebê seja colocado para mamar na sala de parto, na primeira meia hora após seu nascimento, segundo recomendações do Ministério da Saúde .

Para tanto, é importante que a mãe seja orientada em relação ao aleitamento materno desde a primeira consulta de pré-natal: a equipe multiprofissional deve incentivá-lo, informando às mães nas consultas individualizadas e nos grupos de educação em saúde voltados para as gestantes sobre a importância do aleitamento materno, as vantagens, as dificuldades e os mitos envolvidos nesse processo singular vivenciado pela mulher.

Nesse sentido destaca-se que a amamentação não é uma prática meramente instintiva, mas é um ato fortemente influenciado pela vivência da máe-nutriz em sociedade, isto é, o contexto sociocultural se sobrepóe aos determinantes biológicos. Sob esta perspectiva o conhecimento da rede social na qual o indivíduo, nesse caso a nutriz e seus familiares, está inserido permite compreender a dinâmica de suas relaçôes, sendo estas fontes de reflexáo e objetos de estabelecimento de ações de intervenção mais eficazes ${ }^{8}$.

Assim, destaca-se a importância de que os profissionais de saúde conheçam o contexto sociocultural e o cotidiano das lactantes, suas dúvidas, medos e 
expectativas, bem como os mitos e as crenças referentes ao aleitamento materno, para desmistificar as crenças que influenciam de forma negativa na lactação ${ }^{9}$. É importante ressaltar que o profissional de saúde deve apoiar e incentivar a lactante a pôr em prática o aleitamento materno, preparando-a psicologicamente, informando-a sobre a fisiologia da lactação, seus benefícios, como cuidar das mamas e o posicionamento dela e do bebê durante a amamentação ${ }^{8}$.

Entre os mitos que envolvem o aleitamento materno, a ideia de que o leite materno seja fraco, nos dias de hoje, é uma das principais causas da complementação precoce alegada pelas mães, sendo que a comparação do leite humano com o de vaca serviu de fundamentação para essa crença $a^{5}$. A aparência aguada do leite materno, principalmente do colostro, faz com que a mãe considere seu leite inferior, acreditando que náo serve para atender às demandas da criança por diferir daquele tido como forte, o de vaca ${ }^{5}$. A valorizaçáo do leite de vaca em relação ao humano deve-se também à sua composição, com maior quantidade de proteína ${ }^{5}$.

Defende-se que, com a prática de educação em saúde construída pelos profissionais da ESF - especialmente com o trabalho enfermeiro sobre mitos, crenças, medos, preocupaçóes e fantasias relacionados ao aleitamento materno; vantagens e desvantagens do uso da chupeta; vantagens e desvantagens do uso de leite humano; possíveis dificuldades na amamentação e meios de preveni-las -, as dificuldades e preocupaçóes das gestantes em relação ao aleitamento materno poderão ser reduzidas ${ }^{10-11}$.

Nesta pesquisa que realizamos no município de Palmital, as gestantes apontaram que entre as principais dificuldades vivenciadas no aleitamento materno destaca-se a pega e a sucção do bebê no seio materno, além da fissura mamilar. Estudos dizem que no início do aleitamento materno a maioria das mulheres sente uma discreta dor ou desconforto no começo das mamadas, o que pode ser considerado normal ${ }^{12}$. No entanto mamilos muito dolorosos e machucados, apesar de serem muito comuns, não são normais ${ }^{12-13}$. Os traumas mamilares incluem eritema, edema, fissuras, bolhas, marcas brancas, amarelas ou escuras e equimoses ${ }^{11-12}$. A causa mais comum de dor para amamentar se deve a traumas mamilares por posicionamento e pega inadequados ${ }^{12}$. Outras causas incluem mamilos curtos, planos ou invertidos, disfunçôes orais na criança, freio de língua excessivamente curto, sucção não nutritiva prolongada, uso impróprio de bombas de extraçáo de leite, não interrupçáo da sucção da criança antes de retirá-la do peito, uso de cremes e óleos que causam reaçóes alérgicas nos mamilos, uso de protetores de mamilo (intermediários) e exposiçáo prolongada a forros úmidos ${ }^{12}$.
Para reduzir a introdução da alimentação complementar precocemente deve-se orientar a gestante e a nutriz, cabendo ao profissional instruí-las sobre a forma correta de pegar a mama, o posicionamento dela e da criança no ato da amamentaçáo, os cuidados com os mamilos, e discutir certos mitos relacionados com a lactação, possibilitando o sucesso e a manutenção do aleitamento materno ${ }^{5,14}$.

Os profissionais de saúde da ESF podem auxiliar a nutriz incentivando-a a pensar que toda mulher pode amamentar e que seu leite é o alimento ideal para a criança (quantitativa e qualitativamente); elogiando-a em relação aos cuidados com o bebê, quando estes estão corretos; esclarecendo que é comum ter dúvidas sobre o aleitamento materno, e que quando ela não souber que atitude tomar, pode compartilhar suas dificuldades com os profissionais de saúde, que buscarão a melhor forma de ajudar ${ }^{8,15-17}$.

Nessa perspectiva, quando o profissional de saúde considera a cultura materna e a importância da influência da rede social à qual ela pertence na decisão de amamentar e no manejo dessa prática, ele se dispóe a partilhar seu saber com a família e formar uma rede social que dê apoio e suporte à máe nutriz para superar obstáculos e vivenciar de forma plena o aleitamento materno ${ }^{18}$.

Resultados positivos na promoção do aleitamento materno envolvem o comprometimento mútuo entre os profissionais de saúde que atendem as gestantes desde a primeira consulta de pré-natal e elas próprias. A educação em saúde voltada para o incentivo ao aleitamento materno é algo construído em conjunto com as gestantes, e o contexto de vida, os mitos, as crenças e a história de vida delas devem ser valorizados.

\section{Conclusão}

Esta pesquisa permitiu identificar que a maioria das gestantes são orientadas em relação ao aleitamento materno pela ESF no município de Palmital. Destaca-se que as orientaçóes sobre mitos, crenças, medos, preocupaçóes e fantasias relacionados ao aleitamento materno; vantagens e desvantagens do uso da chupeta; vantagens e desvantagens do uso de leite humano; possíveis dificuldades na amamentação e meios de preveni-las (fissura mamilar, empedramento, mastite, pouco leite) são pouco presentes, fato que pode contribuir negativamente para a promoção do aleitamento materno. Nessa perspectiva conclui-se que é importante que os profissionais da ESF conheçam o cotidiano materno e o contexto a que as mães pertencem, suas dúvidas, seus medos e suas expectativas, bem como mitos e crenças referentes ao aleitamento materno, para que possam desmistificar as ideias consolidadas e as influências negativas na lactaçâo. 


\section{Referências}

1. Brasil. Ministério da Saúde. Secretaria de Atenção à Saúde. Departamento de Atenção Básica. Saúde da criança: nutrição infantil: aleitamento materno e alimentação complementar. Brasília, DF: Editora do Ministério da Saúde; 2009. (Cadernos de Atenção Básica, n. 23) (Série A. Normas e Manuais Técnicos).

2. Amorim MM, Andrade ER. Atuação do enfermeiro no PSF sobre aleitamento materno. Perspectivas online [Internet]. 2009 [citado em 2015 fev 18];3(9):93-110. Disponível em: http://bit.ly/2HH0Mwd

3. Ramos LC. Aleitamento materno - efeito de intervenção educativa com equipe de enfermagem na orientação a nutrizes [dissertação]. Goiânia (GO): Universidade Federal de Goiás; 2014.

4. Santana JM, Brito SM, Santos DB. Amamentação: conhecimento e prática de gestantes. Mundo Saúde. 2013;37(3):259-67.

5. Marques ES, Cotta MM, Priore SE. Mitos e crenças sobre o aleitamento materno. Ciênc saúde coletiva. 2011;16(5):2461-68.

6. Brasil. Ministério da Saúde. Secretaria de Políticas de Saúde. Área Técnica de Saúde da Mulher. Parto, aborto e puerpério: assistência humanizada à mulher. Brasília, DF: Ministério da Saúde; 2001.

7. Souza TO, Bispo TC. Aleitamento materno exclusivo e o Programa Saúde da Família da Chapada, município de Aporá (BA). Rev baiana saúde pública. 2007;31(1):38-51.

8. Marques ES, Cotta RMM, Magalhães KA, Sant'Ana LFR, Gomes AP, Siqueira-Batista R. A influência da rede social da nutriz no aleitamento materno. Ciênc saúde coletiva. 2010;15(Supl. 1):1391-400.
9. Maciel APP, Gondim APS, Silva AMV, Barros FC, Barbosa GL, Albuquerque KC, et al. Conhecimento de gestantes e lactantes sobre o aleitamento materno exclusivo. Rev Bras Promoc Saúde. 2013;26(3):311-17.

10. Rodrigues NA, Gomes ACG. Aleitamento materno: fatores determinantes do desmame precoce. Enferm Rev. 2014;17(1):30-48.

11. Souza MAS, Lopes NAR, Borges FV. A importância do enfermeiro da Estratégia Saúde da Família para redução da morbimortalidade materna. Rev Cient Interdisciplinar. 2014;1(1):72-89.

12. Giugliani ERJ. Problemas comuns na lactação e seu manejo. J Pediatr. 2004;80(5):s147-54.

13. Silva MAP, Menezes RCE, Oliveira MAA, Longo-Silva G, Asakura L. Atenção Básica em Alagoas: expansão da Estratégia Saúde da Família, do Nasf e do componente alimentação/nutrição. Saúde Debate. 2014;38(103):720-32.

14. Guerreiro EM, Rodrigues DP, Queiroz ABA, Ferreira MA. Educação em saúde no ciclo gravídico-puerperal: sentidos atribuídos por puérperas. Rev Bras Enferm. 2014;67(1):13-21.

15. King FS, Thomsom Z, Gordon ON, tradutoras. Como ajudar as máes a amamentar. $4^{\mathrm{a}}$ ed. Brasília, DF: Ministério da Saúde; 2001.

16. Souza LMBM, Almeida JAG. História da alimentação do lactente no Brasil - do leite fraco à biologia da excepcionalidade. Rio de Janeiro: Revinter; 2004.

17. Aires RMB, Guimarães LBE. Relato de experiência de um grupo de residentes em enfermagem obstétrica sobre práticas de organização do processo de trabalho. Rev enferm UFPE on line. 2017;11(Supl. 2):1103-7

18. Silva IA. O profissional reconhecendo a família como suporte social para a prática do aleitamento materno. Fam Saúde Desenv. 2001;3(1):7-14.

\section{Como citar este artigo:}

Ferreira MGC, Gomes MFP, Fracolli LA. Aleitamento materno: orientaçóes recebidas por gestantes acompanhadas pela Estratégia Saúde da Família. Rev. Aten. Saúde. 2018;16(55):36-41. 